ARTICULOS ORIGINALES

Rev Chil Salud Pública 2020,

Vol 24(1): 30-39

\section{ESTUDIO DE ALGUNOS BIOMARCADORES PARA INFECCIONES DE TRANSMISIÓN SEXUAL EN UN CENTRO DE INCLUSIÓN SOCIAL VENEZOLANO: PERÍODO 2013-2018}

\author{
STUDY OF BIOMARKERS OF SEXUALLY TRANSMITTED INFECTIONS \\ IN A SOCIAL INCLUSION CENTER IN VENEZUELA: 2013-2018
}

\section{RESUMEN}

Introducción: Las infecciones de transmisión sexual (ITS) se expresan con mayor frecuencia en poblaciones marginadas, como lo son los ciudadanos que se encuentran en situación de calle y con problemas de drogadicción.

Materiales y Métodos: Mediante un estudio de campo descriptivo retrospectivo, se determinó la prevalencia de las ITS que se detallan en los ciudadanos residentes de un Centro de Inclusión Social en Venezuela durante los años 2013 a 2018. Para ello, suero de 280 individuos fue analizado mediante la prueba ELISA de diferentes compañías biotecnológicas.

Resultados: 50 casos $(17,8 \%)$ fueron reactivos a cualquiera de las enfermedades investigadas. El biomarcador de mayor prevalencia durante el lapso estudiado fue el antiHBC con 13,9\% y las menores fueron HBsAg con 0,75\%, VHC con 0,71\% y Treponema pallidum con 2,85\%, así como 2,14\% para VIH. No se detectó ningun caso de HTLV. Del mismo modo, se observó una tasa de co-infección entre hepatitis B y VIH de 2,32\%, entre hepatitis C y VIH de 1,5\% y en dos años se consiguió co-infeccion de hepatitis B y Sifilis con 1,5\% y 5,8\% en el 2014 y 2018 respectivamente.

Discusión: Se encontró que los sujetos acogidos en el Centro de Inclusión Social son un grupo vulnerable a las ITS y las coinfecciones, por lo que deben llevarse a cabo campañas de prevención y pruebas de detección de estas enfermedades en dicha población.

Palabras clave: Infecciones de transmisión sexual, Co-infección, Serotipificación, Diagnóstico, Inmunoensayo ligado a enzimas.

\section{ABSTRACT}

Introduction: Sexually Transmitted Infections (STIS) are most frequently expressed in marginalized populations, such as as homeless individuals or those with substance abuse issues.

Materials and Methods: Through a retrospective descriptive study, the prevalence of various STDs was determined among residents of a Social Inclusion Center in Venezuela from 2013 to 2018. For this purpose, serum from 280 individuals were analyzed with ELISA tests from different biotech companies.

Results: 50 cases $(17.86 \%)$ were sero-reactive to any of the STIs investigated. The most prevalent biomarker during the study period studied was antiHBC (13.9\%) and the lowest prevalences were HBsAg with $0.75 \%$, HCV with $0.71 \%$, and Treponema pallidum with $2.85 \%$, as well as $2.14 \%$ for HIV. No cases of HTLV were detected. Similarly, there was coinfection between hepatitis B and HIV in $2.32 \%$ of cases, between hepatitis $C$ and HIV in 1.5\%, and between syphillis and hepatitis in 1,5\% and 5,8\% of cases (in 2014 and 2018 respectively).

Teodoro Vizcaya Hospital Dr. Egidio Montesinos, El Tocuyo, Estado Lara, Venezuela teodorovizcaya@hotmail.com

Recibido el 11-06-2019 Aceptado el 20-10-2019
Discussion: Individuals in Centers for Social Inclusion are at risk of presenting STIS and Coinfections; therefore, STI prevention campaigns and screenings should be conducted in this vulnerable group.

Keywords: Sexually Transmitted Diseases, Co-infection, Serotyping, Diagnosis, Enzyme-Linked Immunosorbent Assay 


\section{INTRODUCCIÓN}

Una de las principales dimensiones que evidencian el avance alcanzado por un país en la construcción de ciudadanía es la salud colectiva; precisamente, en este derecho se hacen patentes las desigualdades e inequidades y se muestra el nivel de calidad de vida alcanzado por las personas; puesto que el acceso oportuno y la disponibilidad de los servicios públicos de salud junto a otros aspectos configuran el bienestar ciudadano ${ }^{1}$.

En ese sentido, los Centros de Inclusión Social (CIS) son espacios construidos en Venezuela para insertar, capacitar y consolidar a todos aquellos ciudadanos que se encuentran en situación de calle y con problemas de drogadicción. Estos centros están suscritos al programa social conocido como Misiones, que en el discurso oficialista son conceptuadas como estrategias masivas orientadas a garantizar los derechos fundamentales a la población, con énfasis en los sectores más excluidos. Las mismas consisten en un conjunto de programas de carácter social ideados para atender las principales carencias que apuntalan la exclusión y la desigualdad social2,3. En tanto las principales Misiones se debilitaron, apareció otra modalidad de Misiones dirigidas a poblaciones específicas y de carácter asistencial como la Misión Negra Hipólita dirigida a personas en situación de calle y que son albergados en los $\mathrm{CIS}^{4}$. En estos centros se desarrollan acciones y procesos dirigidos al reintegro en sociedad de los ciudadanos en situación de calle y se estima que el tratamiento final de integración y consolidación sea de tres meses, pero todas las fases de tratamiento están calculadas para nueve meses según las condiciones particulares.

Ahora bien, no existe consenso al definir quien es una persona en situación de calle ${ }^{5}$. Sin embargo se acepta que esta población, sujeto principal del presente trabajo, es por definición una población vulnerable, es decir individuos o grupos que tienen limitada su autonomía dado que no pueden proteger sus intereses e integridad personal. Otro aspecto que describe la vulnerabilidad de estas personas es la exclusión social, la cual está estrechamente relacionada con los procesos vinculados a la ciudadanía social, es decir, con aquellos derechos y libertades básicas que tienen que ver con su bienestar.

Por esto, el grupo social allí albergado difiere de otras poblaciones específicas y está en una situación de mayor vulnerabilidad. Hay varios factores que contribuyen a ello, por ejemplo: en las institucio- nes de acogida hay más exposición a la violencia o transmisión de enfermedades infecciosas; estímulos para un comportamiento sexual no responsable debido al confinamiento; problemas para accesar a la red de atención sanitaria; vigilancia epidemiológica precaria; compartir objetos punzantes y carencia de políticas públicas dirigidas a prevenir algunas infecciones en esta comunidad ${ }^{6}$

Por otra parte, las Infecciones de Transmisión Sexual (ITS) son aquellas patologías infecto-contagiosas que se transmiten mediante el contacto oral, vaginal o anal con una persona infectada, a través de los fluidos corporales aunque también existen mecanismos de contagio como la transmisión parenteral. Su incidencia es mayor en áreas urbanas, en solteros, en jóvenes y en usuarios de drogas. Las ITS son el problema de salud pública prevalente en la población mundial por lo que Venezuela no escapa a esta situación y se considera que la trasmisión de estas infecciones se potencia en algunas poblaciones que registran las tasas más altas de ITS, incluidos trabajadores sexuales, hombres homosexuales que practican sexo inseguro, reclusos, poblaciones nómadas y adolescentes. Estos grupos sociales con frecuencia carecen de acceso a servicios de salud apropiados ${ }^{7}$.

En este conjunto de enfermedades se incluyen aquellas que son necesariamente de transmisión sexual, así como aquellas en las que esta puede ocurrir con gran frecuencia, como en el caso de la hepatitis $\mathrm{B}, \mathrm{u}$ otras no siempre exploradas como ITS que no deben ser desatendidas. En la actualidad son catalogadas dentro de este grupo, alrededor de treinta infecciones micóticas, bacterianas, virales o parasitarias, considerándose como emergentes la Hepatitis C y la infección por Mycoplasma genitalium ${ }^{8}$.

Cabe señalar que se conoce como coinfección a la presencia simultánea de dos o más agentes patógenos, en este sentido, la coinfección por el virus de la hepatitis $\mathrm{C}(\mathrm{VHC})$ y el virus de Inmunodeficiencia Humana $(\mathrm{VIH})$ es Ilamada "combinación mortal", pues se estima que uno de cada tres pacientes con VIH presenta también VHC. En América latina y el Caribe se presenta la segunda prevalencia más alta del mundo, con 2,3\% de hepatitis C crónica y $\mathrm{VIH}$. Ambas infecciones son paralelas, pues los dos ribonucleótidos virales poseen vías de transmisión similar, aunque es más fácil contraer primero la infección por $\mathrm{VHC}$ que por $\mathrm{VIH}^{9}$.

El VIH tiene un efecto perjudicial en la infección por el virus de la hepatitis B (VHB), incluyendo un 
mayor riesgo de cronicidad, fibrosis hepática, carcinoma hepatocelular $(\mathrm{CHC})$ y mortalidad por todas las causas, lo que ha llevado a investigadores a caracterizar el genotipo del VHB en pacientes coinfectados con VIH para conocer la asociación entre mutaciones genéticas específicas y la severidad de fibrosis hepática ${ }^{10}$.

Las poblaciones de movilidad restringida como las poblaciones circunscritas a programas de integración social, poblaciones carcelarias o en areas de conflicto social, tambien se caracterizan como grupos de riesgo para infecciones transmitidas principalmente por vía parenteral o sexual. Estudios realizados en privados de libertad brasileiros evidencian la vulnerabilidad de esa población a la transmisión parenteral de VHC y de HIV a través del uso de drogas inyectables y a la transmisión mediante prácticas sexuales sin protección, además de asociarse ese cuadro a las condiciones de confinamiento, marginalidad y servicios de salud precarios ${ }^{11}$.

Aunado a ello se presenta el tratamiento intermitente de antirretrovirales en algunos pacientes, por ejemplo informes de la Organización Panamericana de la Salud (OPS) muestran que Venezuela fue el país de América Latina con el mayor número de episodios de desabastecimiento de antirretrovirales (TAR) reportados en $2012^{12}$.

Dada la singularidad de la situación y de los sujetos participantes en la investigación, el objetivo de este estudio fue determinar la prevalencia de algunas ITS en ciudadanos albergados en un Centro de Inclusión Social del estado Lara en Venezuela mediante los biomarcadores no invasivos de mayor accesabilidad y uso, así como también destacar las posibles coinfecciones que pudiesen presentarse en la misma dependencia durante el periodo 2013 a 2018.

\section{MATERIAL Y MÉTODO}

Tipo de estudio: Se realizó un estudio descriptivo retrospectivo con ciudadanos residentes de un centro de inclusión social para hombres, mayores de edad, provenientes de diversas zonas del pais, que fueron trasladados hasta la zona sur del estado Lara en Venezuela considerando sus deseos expresos. Dichos pacientes fueron atendidos en su centro de residencia, cuyas muestras biológicas fueron luego trasladadas al Laboratorio del Hospital Dr. Egidio Montesinos de la ciudad de El Tocuyo, en el estado Lara, durante el período 2013 a 2018, lo que constituyó un universo efectivo de 280 sujetos.

Para la atención de dichos ciudadanos se establecieron criterios de inclusión tales como: paciente voluntario que manifestase su deseo de participar en el estudio así como desconocimiento del status serológico en relación con las infecciones indagadas. Como criterios de exclusión se consideró unicamente la manifestación explícita de no querer participar en la investigación proyectada.

Determinación serológica de las ITS: La sangre se tomó por venopunción al vacío. Se buscó identificar la presencia de alguna de las ITS mediante la detección del antígeno de superficie del virus de la hepatitis B (HBsAg) o los anticuerpos contra el antígeno del núcleo (anti-HBc) del mismo virus, que pudiesen estar presentes en el suero. Conjuntamente se indagó la presencia de anticuerpos contra el virus de la hepatitis $\mathrm{C}$ (anti VHC), anticuerpos frente al virus T-linfotrópico humano de tipo I y II (anti HTLV) y anticuerpos contra el virus de la inmunodeficiencia humana (anti VIH-1 y anti VIH-2). De igual manera se buscó la presencia de anticuerpos específicos contra el Treponema pallidum que constituyen los biomarcadores mas comunes y disponibles que se realizan en el Laboratorio de la entidad descrita.

\section{Antígeno de superficie del virus de hepatitis B (HB- sAg).}

Para realizar esta prueba se utilizó Murex HbsAg Version 3 que es una técnica ELISA de Diasorin específica para la detección del antígeno de superficie del virus de la hepatitis B (HBsAg). Utiliza un anticuerpo anti-HBsAg en fase sólida, que se une al antígeno presente en el suero estudiado, el cual reacciona frente a un conjugado marcado con una enzima, la que en contacto con un sustrato apropiado, desarrolla una reacción colorimétrica, que puede ser leída visual o instrumentalmente ${ }^{13}$.

\section{Anticuerpos contra el antígeno core del virus de la hepatitis B (anti-HBc).}

El equipo Murex anti-HBc (total) de la casa biotecnológica Diasorin, fue el usado en el período estudiado. Es un ensayo por inmunoabsorción ligado a enzimas (ELISA) de tercera generación que utiliza micropocillos recubiertos de antígeno core recombinante frente al virus de la hepatitis B. Las muestras y los controles se incuban en los pocillos y el anti-HBc presente en la muestra se une al $\mathrm{HBcAg}$. El exceso de anticuerpos se elimina mediante lavado. El conjugado se añade a los pocillos y durante la 
segunda incubación, el conjugado se une al $\mathrm{HBcAg}$ de la superficie del pocillo no unido a los anticuerpos anti-HBc de la muestra. Después del lavado, se añade a los pocillos una solución que contiene tetrametilbencidina y peróxido de hidrógeno. En los pocillos que no contienen anti-HBc y por tanto, conjugado unido, se desarrolla un color azul cuya intensidad del color se puede determinar espectrofotométricamente ${ }^{14}$.

\section{Anticuerpos contra el virus de la hepatitis C (VHC)}

Se estudiaron mediante el equipo Murex anti-HCV de Diasorin que es un inmunoensayo enzimático que detecta anticuerpos contra el VHC en suero o plasma humano. El fundamento y técnica es similar a la de los anticuerpos contra el antígeno core del virus de la Hepatitis B, sólo que en esta prueba se buscan anticuerpos contra cuatro regiones diferentes de la proteína viral (núcleo, NS3, NS4 y NS5) del VHC. La cantidad de conjugado unido y por lo tanto el color en los pocillos, está directamente relacionada con la concentración de anticuerpos en la muestra ${ }^{15}$.

\section{Anticuerpos frente al virus T-linfotrópico humano de tipo I y II (HTLV-I y II)}

Para este análisis se recurrió al ensayo Murex HTLV I+Il de Diasorin, que utiliza micropocillos recubiertos de péptidos sintéticos correspondientes a las regiones inmunodominantes de las proteínas de las envolturas del HTLV-I y del HTLV-II y una proteína recombinante transmembranal del HTLV-II. Las muestras se incuban en los pocillos y los anticuerpos frente al HTLV-I o II presentes en la muestra se unen a los antígenos de los micropocillos. Se añade el conjugado que se vincula a los anticuerpos específicos ya unidos a los antígenos de los pocillos. Después del lavado se agrega en los pocillos una solución con tetrametilbencidina (TMB) y peróxido de hidrógeno. En los pocillos con el conjugado unido se desarrolla un color violeta que es directamente proporcional a la concentración de anticuerpos frente al HTLV presente en la muestra ${ }^{16}$.

\section{Anticuerpos contra el Treponema pallidum.}

Se utilizó ICE* Syphilis de ABBOTT diagnostics, con técnica y fundamento similares a lo descrito en las técnicas anteriores. Se basa en la exposición de anticuerpos a los epítopos immunodominantes del T. pallidum Las muestras se incuban en los pozos y si los anticuerpos específicos contra T. pallidum están presentes, son capturados por sus antígenos relacionados. La muestra, incluyendo cualquier anticuerpo no unido, se elimina por lavado. Luego se agrega conjugado que es capturado por cualquier anticuerpo específico ya unido a la placa. El conjugado sin unir se lava y se añade seguidamente una solución que contiene TMB y peróxido de hidrógeno. Los pocillos reactivos desarrollan un color púrpura que se lee visualmente o mediante espectrofotómetro ${ }^{17}$.

\section{Anticuerpos contra el virus de inmunodeficiencia humana. (VIH)}

Distribuido como Murex HIV Ag/Ab Combination de la casa ABBOTT diagnostics, este inmunoensayo enzimático detecta la presencia del $\mathrm{VIH}$ confrontando los posibles anticuerpos contra el núcleo del virus o los anticuerpos contra las glicoproteínas de su envoltura, en un fundamento y procedimiento similar a lo que se ha venido describiendo para los otros marcadores virales estudiados. Las muestras se incubaron en los pozos, en donde si había anticuerpos, se unirían a los antígenos del pocillo. Luego los anticuerpos se lavaron y en un paso posterior, se añadió el conjugado, se lavó nuevamente y se agregó TMB y peróxido de hidrógeno, lo que desarrolló un color verde azulado en los casos reactivos a la infección ${ }^{18}$.

En las técnicas por ELISA, las muestras con valores de absorbancia inferiores al valor de la línea de corte (cut off) se consideraron no reactivas al biomarcador indagado, de acuerdo con el límite de sensibilidad de la técnica. Las muestras con valores de absorbancia superiores o iguales al valor de la línea de corte se consideraron inicialmente reactivas

Análisis estadístico: Los datos obtenidos de los pacientes para las pruebas HTLV, VIH, anticuerpos contra Treponema pallidum y los anticuerpos contra hepatitis B y C, fueron ordenados y analizados estadísticamente mediante el programa SPSS statistics versión 22 para lo cual se tomó nivel de significación estadística de 0,05. Se aplicó estadística descriptiva, mediante frecuencias absolutas, relativas y tablas de contingencia. De igual manera se calculó la frecuencia de casos detectados y porcentaje específico de reactividad a las ITS por marcador analizado y por año de ocurrencia, considerando lo reportado en los respectivos libros de control, pero características como edad, zona de procedencia, tiempo de ingreso o uso de drogas no pudieron ser evaluadas. Por otra parte, es pertinente acotar que ante la carencia de cifras comparativas para estos centros de 
albergue de ciudadanos, en esta investigación se recurre en ciertos aspectos a la data reportada para recintos peninteciarios y asi poder comparar algunos indicadores de ITS.

Aspectos Bioéticos: Los ciudadanos aceptaron mediante el Consentimiento informado que sus muestras biológicas pudiesen ser objeto de algun exámen posterior. Los aspectos técnicos expresados a través del protocolo de investigación obtuvieron la aprobación mediante respuesta informada del Comité de Bioética del Hospital Dr. Egidio Montesinos, que es la institución prestadora de los servicios de salud del municipio Morán, considerando que el estudio era coherente con la Declaración de Helsinki, que las muestras eran necesarias para la consecución de los objetivos del estudio, que no existía evidencia de que el sujeto hubiese manifestado su oposición a la utilización de la muestra y además que la investigación no perjudicaba los intereses del sujeto fuente, como lo señala el Código de ética para la vida que se cumple al realizar investigaciones en Venezuela ${ }^{19}$.

\section{RESULTADOS}

Desde el punto de vista sociodemográfico, los ciudadanos son personas que poseen estudios de nivel básico o algunos no culminan la educación secundaria. Sin ocupación estable, presentan a menudo adicciones o afectaciones psicológicas que pueden ser resueltas en la medida que son atendidas por especialistas. En general no tienen acceso a servicios sanitarios y sufren en primera persona la violencia y segregación de la calle.

Al revisar los hallazgos inmunológicos objeto de la investigación, se encontró que del total de muestras estudiadas, cincuenta resultaron positivas al contacto con alguno de los agentes etiológicos de las ITS en cuestión, lo que demostró una prevalencia de $17,86 \%$ a cualquiera de las infecciones investigadas. Estas cifras permiten reconocer que el año con mayor prevalencia a infección por alguna ITS fue el $2015(23,9 \%)$ y el que presentó la menor cifra global de infección fue el año 2017 (3,4\%). La prevalencia mayor por biomarcador en el lapso estudiado fue de $13,9 \%$ para el antiHBc y la menor para $\mathrm{HBsAg}$ con $0,75 \%$, del mismo modo se evidencia que no se

Tabla 1. Prevalencia de ITS por biomarcador en un CIS del estado Lara en Venezuela, periodo 2013-2018.

\begin{tabular}{|c|c|c|c|c|c|c|c|}
\hline \multirow{2}{*}{$\begin{array}{c}\text { EVOLUCIÓN } \\
\text { DE LA ATENCIÓN }\end{array}$} & \multicolumn{6}{|c|}{ AÑOS } & \multirow[b]{2}{*}{ TOTAL $(\mathrm{N})$} \\
\hline & 2013 & 2014 & 2015 & 2016 & 2017 & 2018 & \\
\hline Ciudadanos atendidos & 43 & 133 & 46 & 12 & 29 & 17 & 280 \\
\hline Seropositivos a alguna ITS (\%) & $\begin{array}{c}9 \\
(20,93)\end{array}$ & $\begin{array}{c}24 \\
(18,04)\end{array}$ & $\begin{array}{c}11 \\
(23,9)\end{array}$ & $\begin{array}{c}2 \\
(16,6)\end{array}$ & $\begin{array}{c}1 \\
(3,44)\end{array}$ & $\begin{array}{c}3 \\
(17,64)\end{array}$ & $\begin{array}{c}50^{*} \\
(17,86)\end{array}$ \\
\hline $\begin{array}{c}\text { Susceptibles a alguna ITS } \\
(\%)\end{array}$ & $\begin{array}{c}34 \\
(79,06)\end{array}$ & $\begin{array}{c}109 \\
(81,9)\end{array}$ & $\begin{array}{l}35 \\
(76)\end{array}$ & $\begin{array}{c}10 \\
(83,4)\end{array}$ & $\begin{array}{c}28 \\
(96,56)\end{array}$ & $\begin{array}{c}14 \\
(82,36)\end{array}$ & $\begin{array}{c}230 \\
(82,14)\end{array}$ \\
\hline $\begin{array}{c}\mathrm{HbsAg} \\
(\%)\end{array}$ & $\begin{array}{c}1 \\
(2,32)\end{array}$ & $\begin{array}{c}1 \\
(0,75)\end{array}$ & 0 & 0 & 0 & 0 & $\begin{array}{c}2 \\
(0,71)\end{array}$ \\
\hline $\begin{array}{c}\text { antiHBc } \\
(\%)\end{array}$ & $\begin{array}{c}8 \\
(18,6)\end{array}$ & $\begin{array}{c}20 \\
(15)\end{array}$ & $\begin{array}{c}9 \\
(19,56)\end{array}$ & 0 & 0 & $\begin{array}{c}2 \\
(11,76)\end{array}$ & $\begin{array}{c}39 \\
(13,92)\end{array}$ \\
\hline $\begin{array}{c}\mathrm{HCV} \\
(\%)\end{array}$ & 0 & $\begin{array}{c}2 \\
(1,50)\end{array}$ & 0 & 0 & 0 & 0 & $\begin{array}{c}2 \\
(0,71)\end{array}$ \\
\hline $\begin{array}{l}\text { HIV } \\
(\%)\end{array}$ & $\begin{array}{c}2 \\
(4,65)\end{array}$ & $\begin{array}{c}3 \\
(2,25)\end{array}$ & 0 & 0 & $\begin{array}{c}1 \\
(3.44)\end{array}$ & 0 & $\begin{array}{c}6 \\
(2,14)\end{array}$ \\
\hline $\begin{array}{c}\text { HTLV } \\
(\%)\end{array}$ & 0 & 0 & 0 & 0 & 0 & 0 & 0 \\
\hline $\begin{array}{c}\text { Treponema pallidum } \\
(\%)\end{array}$ & 0 & $\begin{array}{c}4 \\
(3)\end{array}$ & 0 & $\begin{array}{c}2 \\
(16,6)\end{array}$ & 0 & $\begin{array}{c}2 \\
(11,76)\end{array}$ & $\begin{array}{c}8 \\
(2,85)\end{array}$ \\
\hline
\end{tabular}

*El número de ciudadanos seropositivos no coincide con el número de pruebas reactivas pues existe coinfección en algunos casos. 
detectó algún caso de HTLV como puede observarse en la Tabla 1.

Al observar los resultados sobre la hepatitis, el marcador antiHBc se mantiene claramente elevado respecto a las cifras de los otros biomarcadores en todo el período estudiado, por lo que el mayor riesgo para los ciudadanos es la hepatitis B (Figura 1) dado el porcentaje de casos detectados en el lapso indicado.

Por otra parte, se pudieron observar casos de coinfección de ITS en algunos ciudadanos, por lo que al estudiarlos en detalle se encontró una prevalencia de coinfección entre hepatitis B y VIH de 2,32\%, coinfeccion de hepatitis $\mathrm{C}$ y VIH de $1,5 \%$ y en dos años se consiguió coinfeccion de hepatitis B y Sífilis

Figura 1. Distribución porcentual específica de ITS en un CIS del estado Lara en Venezuela, periodo 2013-2018.

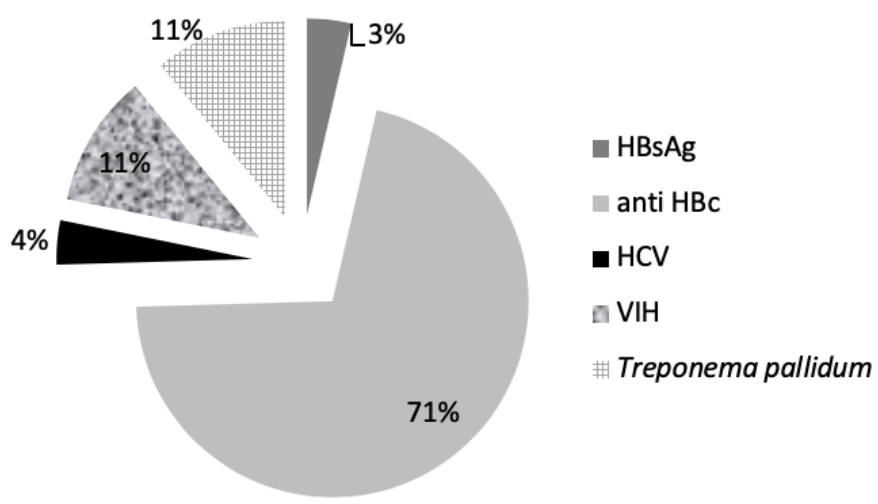

Tabla 2. Prevalencia de coinfección de ITS en un CIS del estado Lara en Venezuela.

\begin{tabular}{|c|c|c|c|c|c|c|}
\hline \multirow{3}{*}{ Biomarcador } & \multicolumn{6}{|c|}{ Prevalencia } \\
\hline & \multicolumn{2}{|c|}{ Año 2013} & \multicolumn{2}{|c|}{ Año 2014} & \multicolumn{2}{|c|}{ Año 2018} \\
\hline & $\mathbf{N}$ & $\%$ & $\mathbf{N}$ & $\%$ & $\mathbf{N}$ & $\%$ \\
\hline Seropositivos & 9 & 20,93 & 24 & 18,04 & 3 & 17,6 \\
\hline antiHBc & 8 & 18,6 & 20 & 15 & 2 & 11,76 \\
\hline HIV & 2 & 4,65 & 3 & 2,25 & 0 & 0 \\
\hline Sífilis & 0 & 0 & 4 & 3 & 2 & 11,76 \\
\hline $\mathrm{HCV}$ & 0 & 0 & 2 & 1,5 & 0 & 0 \\
\hline Coinfección VHB/VIH (antiHBc/VIH) & 1 & 2,32 & 0 & 0 & 0 & 0 \\
\hline $\begin{array}{l}\text { Coinfección VHC/ VIH } \\
\text { (anti VHC/antiVIH) }\end{array}$ & 0 & 0 & 2 & 1,5 & 0 & 0 \\
\hline Coinfección VHB/Sífilis (anti HBc/ Sífilis) & 0 & 0 & 2 & 1,5 & 1 & 5,88 \\
\hline
\end{tabular}


con 1,5\% y 5,8\% para los años 2014 y 2018 respectivamente, como se aprecia en la Tabla 2.

\section{DISCUSIÓN}

No es fácil determinar la frecuencia con que se producen las ITS en estos centros de acogida de ciudadanos al igual que en otros como el medio penitenciario debido a restricciones legales y sociales. Por no existir algún trabajo previo no se dispone de datos específicos nacionales ni a nivel de este tipo de centros, que permitan comparar estos hallazgos, por lo que se recurrió a cifras reportadas para centros de reclusión, que parecieran ser lo más cercano desde el punto de vista sanitarista.

En este sentido y al evaluar la prevalencia de ITS, es oportuno recalcar que usualmente se reconoce a la blenorragia, sífilis y al VIH como enfermedades de declaración obligatoria, sin embargo se proporciona poca información epidemiológica sobre las hepatitis virales o sobre el HTLV, además que usualmente no se indagan otras ITS como las causadas por Candida albicans, Molluscum contagiosum o Ureaplasma urealyticum entre otras.

No obstante, al reconocer los diferentes factores de riesgo relacionados con las ITS que se presentan en grupos poblacionales recluidos, se ha encontrado que los hombres siguen constituyendo la población más vulnerable para contraer dichas infecciones debido al consumo de sustancias psicoactivas, compartir elementos de uso personal, mantener relaciones sexuales sin protección o realizarse tatuajes ${ }^{20}$ y en este sentido los CIS pudieran asemejarse epidemiológicamente a algunos recintos carcelarios,

Por consiguiente, al encontrarse $17,8 \%$ de preeminencia para alguna de las ITS investigadas es oportuno reseñar que en Venezuela se han encontrado valores de hasta un $26 \%$ en algunas cárceles, de los cuales un $16,2 \%$ de su población presentaba anticuerpos contra el núcleo del virus de hepatitis B, el $6 \%$ tenía anticuerpos antitreponémicos y $4 \%$ revelaba anticuerpos contra el VIH21.

Si se detallan los resultados sobre hepatitis, el valor encontrado (13,92\%) es alto respecto a lo reportado para Venezuela con el antiHBc como biomarcador. De igual manera si se estudia la prevalencia encontrada para la hepatitis B por el biomarcador más difundido que es el HBsAg, se observa que el valor de $0,71 \%$ es mayor al compararlo con la prevalencia encontrada para Venezuela $(0,48 \%)$, para la América latina $(0,33 \%)$ y para la región panamericana
$(0,28 \%)$ según el último reporte de la Organización Panamericana de la Salud (OPS) ${ }^{22}$. Estas cifras son concordantes con otros estudios que revelan que las ITS mas frecuentes en hombres internados son la hepatitis B así como el VIH, pero tambien señalan en menor proporción M. contagiosum, C. albicans y pediculosis púbica. ${ }^{21}$

Al revisar la prevalencia de infección por hepatitis $C$, la cifra descubierta de sujetos serorreactivos $(0,71 \%)$ representa el doble de lo reportado para Venezuela que asciende a $0,34 \%$ (22), cifra que además es superior a lo denunciado en América latina y el Caribe $(0,65 \%)$ pero similar al $0,73 \%$ en la región de las Américas ${ }^{23}$.

$\mathrm{Al}$ analizar los resultados detectados en este estudio para el VIH (2,14\%), la prevalencia reportada es coherente con los reportes de la OPS para Venezuela y coincide con las prevalencias de otros países de la subregión como Colombia, Brasil, Argentina y Bolivia ${ }^{33}$, sin embargo para una población poco estudiada como los residentes de los CIS o similares, se ha llegado a reportar una diversidad en la prevalencia de VIH que está dentro del $1 \%$ en poblaciones recluidas ${ }^{24}$ hasta el $8,2 \%$ para los hombres en situación de calle ${ }^{25}$.

Es importante enfatizar que la condición de vulnerabilidad ante el VIH/SIDA se incrementa en la población con bajo nivel educativo, bajos niveles socioeconómicos y de hombres que tienen sexo sin protección con hombres ${ }^{26}$. Estas condiciones sociales obervadas a menudo en ciudadanos en situación de calle continúan siendo barreras que afectan la equidad en las oportunidades en salud.

Al describir la infección por T. pallidum mediante el valor revelado en esta investigación $(2,85 \%)$ se aprecia un porcentaje superior en este biomarcador respecto a lo referido para Venezuela, que se sitúa en $1,55 \%$ y lo ubica como el país con la prevalencia más alta de Latinoamérica ${ }^{22}$, pero son cifras que se comparan usualmente con las de poblaciones específicas o muy seleccionadas como pueden ser los donantes de sangre, Al no disponer de datos específicos en el pais relacionados con este tipo de centros, que permitiesen comparar estos hallazgos, se acudió a valores divulgados para centros de reclusión que oscilan entre 1,53\% de los test realizados ${ }^{27}$ y $6,12 \%$ detectado ${ }^{21}$.

Ahora bien, al determinar la prevalencia del virus linfotrópico de células T humanas (HTLV) I/II en estos ciudadanos, no se encontró algún caso en el lapso estudiado, situación que es coincidente con 
las bajas cifras reportadas para Venezuela ${ }^{22}$.

Al revisar los casos de infecciones múltiples, se encontró una prevalencia de coinfección $\mathrm{VHB} / \mathrm{VIH}$ de $2,32 \%$, muy por debajo de lo encontrado por otros investigadores ${ }^{28,29}$ quienes reportaron seroreactividad de $\mathrm{VIH}$ con al menos un marcador de hepatitis B (HBsAg o antiHBc), los cuales también son inferiores a lo revelado por estudios similares en las regiones norte y sur de Brasil, que mostraron resultados mayores al 23\% 30,31 , lo que debe llevar a considerar la región geográfica y los factores de riesgo y transmisión a los que se expone la población estudiada.

La importancia de estudiar esta dupla infecciosa deriva del hecho que el sexo masculino, el aumento de la edad y el estadio clínico avanzado de la infección por el VIH, son los principales factores de riesgo de padecer de fibrosis/cirrosis hepática ${ }^{32}$.

En este orden de ideas, el virus de la inmunodeficiencia humana $(\mathrm{VIH})$ genera otra de las infecciones más comúnmente encontradas en pacientes con el VHC que tiene una epidemiología similar al virus de la inmunodeficiencia humana $(\mathrm{VIH})$ y ambos se transmiten principalmente por la vía sexual o parenteral. Por lo tanto, la coinfección VHC/NIH se observa con frecuencia en las poblaciones vulnerables con tales vías de transmisión ${ }^{33}$, como es el caso de los ciudadanos atendidos en los centros de inclusión social. En este sentido se ha reportado que la tasa de $\mathrm{VIH}$ en personas sin hogar era de $7,2 \%$ y del $\mathrm{VHC}$ de $11,7 \%$, siendo el consumo de drogas por vía parenteral el principal factor de riesgo de infección tanto de $\mathrm{VIH}$ como de $\mathrm{VHC}^{34}$.

Particularmente en este estudio y específicamente para el año 2014 se desveló una prevalencia de 1,5\% de coinfección entre Hepatitis C y VIH, muy cercano a lo encontrado por otros investigadores quienes señalaban $1,67 \% \%^{35}$ y $2,32 \% 28$ respectivamente, pero muy debajo de las cifras de la prevalencia general de la coinfección de HIV con VHC que se ha estimado en cerca del $6 \%{ }^{36}$.

La existencia de anticuerpos antiVHC y antiVIH en las muestras analizadas indica que esta población constituye un grupo susceptible de padecer hepatitis C, VIH y coinfecciones VHCNIH. Considerando que los estudios relacionados con la coinfección del VHC/VIH en las cárceles u otros centros de internado son raros o inexistentes; se espera que este puede ser un dato preliminar sobre la coinfección en poblaciones recluidas. Sin embargo, los resultados deben analizarse con precaución, dadas las características de muestreo que limitaron el análisis descriptivo de esta población.

Por otro lado, la coinfección VHB y Sífilis fue la más observada de las infecciones múltiples con una prevalencia no constante de $1,5 \%$ y $5,88 \%$ en los años 2014 y 2018 respectivamente, cifras cercanas al 4,79\% de reactividad simultánea de VHB con sífilis descrita en otro trabajo ${ }^{37}$, pero alejadas de lo reportado en un estudio uruguayo ${ }^{38}$ que situó en su investigación una prevalancia de 14\%.

Es importante acotar que la mayoría de las reactividades simultáneas que se presentan en biomarcadores para agentes infecciosos trasmitidos especialmente por vía sexual, están representadas por las de hepatitis B seguidas por la de Sífilis ${ }^{39}$.

Para finalizar, junto a las dificultades que se presentan para definir quién puede ser considerada como una persona sin hogar en los países menos desarrollados, se suma la dificultad de acceder a información sobre el número, características y necesidades de los colectivos en situación de exclusión social.

A través de los resultados se encontró que los sujetos acogidos en el CIS son un grupo social vulnerable a las ITS y las coinfecciones, por lo que deben llevarse a cabo campañas de prevención y pruebas de detección de estas enfermedades en este colectivo. Asimismo es importante visibilizar la realidad de estas personas que viven en el anonimato con el objetivo de mejorar sus condiciones de vida, de salubridad y lograr el respeto a los derechos humanos que les asisten.

Aunque es un estudio realizado en tan solo un Centro de Inclusión Social, los resultados podrían extrapolarse a otros recintos con las mismas características, ya que la población residente circula por otros CIS del ámbito nacional mientras se adaptan a la vida social productiva.

\section{Conflicto de intereses}

Declaro no tener algún tipo de conflicto de intereses, ni ninguna relación económica, personal, política, interés financiero ni académico que haya influido en mi juicio. Declaro, además, no haber recibido ningún tipo de beneficio monetario, bienes ni subsidios de alguna fuente que pudiera tener interés en los resultados de esta investigación.

\section{REFERENCIAS BIBLIOGRÁFICAS}

1. Delgado-Blanco A. El derecho a la salud como dimensión de la ciudadanía social en América Latina y Venezuela VJ. [en línea]. 2018 [consultado el 08 jun 
2019];67(137). Disponible en: https://revistas.javeriana.edu.co/index.php/vnijuri/article/view/2233

2. Alvarado-Chacín N. Las estrategias de inclusión social en Venezuela: un acercamiento a la experiencia de las misiones. Convergencia. 2009;16(51):85-128.

3. Carosio A. Política Social en Venezuela. Las Misiones Sociales. Entornos 2016;29(2):61-73.

4. D’Elia Y, Quiroz C. Las Misiones Sociales: ¿Una Alternativa para Superar la Pobreza? Caracas: Instituto Latinoamericano de Investigaciones Sociales (ILDIS). Oficina en Venezuela de la Fundación Friedrich Ebert; 2010.

5. Berríos-Ballesteros A, Suárez-Rodríguez A, Rodriguez K, Vásquez-Cabrera J. Personas en situación sin hogar en León (Nicaragua): definición, número, características y necesidades básicas. Documentos de Trabajo IELAT, Universidad de Alcalá No 102, Septiembre 2017.

6. Dolan K, Wirtz AL, Moazen B, Ndeffo-mbah M, Galvani A, Kinner SA, et al. Global burden of HIV, viral hepatitis, and tuberculosis in prisoners and detainees. Lancet. 2016;388(10049):1089-1102.

7. Reyes A. Infecciones de transmisión sexual. Un problema de salud pública en el mundo y en Venezuela. Comunidad y Salud. 2016;14(2):63-71.

8. Centers for Disease Control and Prevention. Recommendation and Reported. Sexually Transmitted Diseases Treatment Guidelines 2015. (MMWR) [en línea] 2015. [consultado el 08 de jun 2019]. June 5;64(3):1136. Disponible en: http://www.cdc.gov/mmwr/pdf/rr/ rr6403.pdf

9. Lescay-Bell O, Cabezas-Niubo EP, Suárez-Suárez MJ, Fernández-Duharte J, Martén-Maren D. Coinfección por el virus de la hepatitis $\mathrm{C}$ y el virus de la inmunodeficiencia humana en una población de riesgo. MEDISAN. 2016;20(10):2224-2229.

10. Grant J, Agbaji O, Kramvis A, Yousif M, Auwal M, Penugonda $S$, et al. Hepatitis $B$ virus sequencing and liver fibrosis evaluation in HIV/HBV co-infected Nigerians. Trop Med Int Health. 2017;22(6):744-754.

11. Gabe C, Muller-Lara G. Prevalência de anti-HCV, anti-HIV e co-infecção HCV/HIV em um presídio feminino do Estado do Rio Grande do Sul. RBAC. 2008;40(2):87-89.

12. Organización Panamericana de la Salud. Tratamiento antirretroviral bajo la lupa: un análisis de salud pública en Latinoamérica y el Caribe 2013. Washington DC: OPS; 2013.
13. Instituto de Salud Pública. Ministerio de salud. Virus hepatitis B (Antígeno de superfície HBsAg) [en línea] [consultado el 08 de jun de 2019]. Disponible en: http://www.ispch.cl/virus-hepatitis-b-antigeno-de-superficie-hbsag

14. Murex anti-HBc (total). Enzimoinmunoanálisis para la detección de anticuerpos frente al antígeno core del virus de la hepatitis B (anti-HBc) en suero o plasma humanos [en línea]. Dartforg UK; 2009 [Consultado el 08 de jun de 2019]. p. 1-8. Disponible en: http:// www.annardx.com/productos/images/productos/diagnostica/infecciosas/Murex-Anti-HBc-Total.pdf

15. WHO Prequalification of In Vitro Diagnostics Programme. PUBLIC REPORT Product: Murex anti-HCV (version 4.0) [en línea]. Kyalami; [consultado el 08 de jun de 2019]; 2015. p.1-16. Disponible:https://www. who.int/diagnostics_laboratory/evaluations/150608_ final_report_0164_059_00_murex_hcv_vesion_4_0. pdf

16. Murex HTLV I + II. Enzimoinmunoanálisis cualitativo para ladetección de anticuerpos frente al virus T-linfotrópicohumano de tipo I y II (HTLV-I y HTLV-II) en suero y plasma [en línea]. Dartford UK: DiaSorin S.a.P. [consultado el 08 de jun de 2019]; 2009. p. 1-8. Disponible:http://www.annardx.com/productos/images/ productos/diagnostica/infecciosas/murex-htlv-iiipdf. pdf

17. ICE* Syphilis Enzimoinmunoanálisis para la detección de anticuerpos frente a Treponema pallidum [en línea]. Darrtford UK: DiaSorin S.a.P. [consultado 08.06.2019]; 2009. p. 1-8. Disponible en: http://www.annardx. com/productos/images/productos/banco-de-sangre/ infecciosas/Murex-Ice-Syphilis.pdf

18. Murex HIV Ag/Ab Combination. Enzimoinmunoanálisis para la detección mejorada de la seroconversión frente a los virus de la inmunodeficiencia humana tipo 1 (VIH-1, grupoO del VIH-1) y la detección de los anticuerpos anti-VIH-2 [en línea] [consultado el 08 de jun de 2019]; 2009. p. 1-9. Disponible en: http://www.annardx.com/productos/images/productos/diagnostica/ infecciosas/hiv-combopdf.pdf

19. Normas para la investigación en muestras biológicas. En: Código de ética para la vida, Caracas: Ministerio del Poder Popular para la Ciencia, Tecnología e Industrias Intermedias; 2011, [en línea]. p. 71-76. [Consultado 08.06.2019]. Disponible en: http://www2.ula.ve/ cdcht/dmdocuments/codigo_etica_\%20FONACIT.pdf

20. Pérez-Morente MA, Cano-Romero E, Sánchez-Ocón MT, Castro-López E, Jiménez-Bautista F, Hueso-Mon- 
toro C. Factores de riesgo relacionados con las infecciones de transmisión sexual. Rev Esp Salud Pública. 2017;91(1):e1-e7.

21. Posada A, Díaz Tremarias, M. Infección por VIH, Hepatitis B y Sífilis en reclusos de centros penitenciarios de Venezuela, 1998-2001. Rev Esp Sanid Penit. 2008;10:73-79.

22. Organización Panamericana de la Salud. Suministro de sangre para transfusiones en los países de Latinoamérica y del Caribe, 2014 y 2015 [en línea]. Washington, D.C: OPS; 2017 [consultado el 08 de jun de 2019]. 273 p. Disponible en:http://iris.paho.org/xmlui/ bitstream/handle/123456789/34082/9789275319581 -spa.pdf? sequence $=1$ \&isAllowed $=y$

23. Organización Panamericana de la Salud-OPS. Las hepatitis B y C bajo la lupa: la respuesta de Salud Pública en la Región de las Américas 2016 [en línea]. Washington, D.C: OPS; 2016. [consultado el 08 de jun de 2019]. Disponible en: http://iris.paho.org/xmlui/ bitstream/handle/123456789/31447/9789275319291 -spa.pdf? sequence $=5$ \&isAllowed $=y$

24. Sousa KAA, Araújo TME, Teles SA, Rangel EML, Nery IS. Factors associated with HIV prevalence in a prison population. Rev Esc Enferm USP. 2017;51:e03274.

25. Berbesí D, Segura-Cardona A, Caicedo B, Cardona-Arango D. Prevalencia y factores asociados al VIH en habitante de calle de la ciudad de Medellín, Colombia. Rev Fac Nac Salud Pública. 2015;33(2):200205.

26. Alarcón AM, Chahin C, Muñoz S, Wolff M, Northland, R. Perfil de personas con infección por VIH/SIDA: diferencial étnico, económico y socio-cultural en Chile. Rev Chilena Infectol. 2018;35(3):276-282.

27. Calero G, Fratti J, Larrañaga J, Gallo S, Hernández T, Bittar G. Situación de salud de personas privadas de libertad de sexo masculino que ingresaron al sistema penitenciario uruguayo entre Enero y Junio 2016. An Facultad Med. 2017;4(Supl 1):109-126.

28. dos Santos OP, Ramos de Souza M, Borges CJ, Noll M, Campos-Lima F, de Sá Barros P. Hepatites B, C e Sífilis: prevalência e características associadas à coinfecção entre soropositivos, Cogitare Enferm. 2017;(22)3:e51693.

29. Figueroa-Agudelo FN, Cabrera-Garcia HB, Zapata-Cárdenas A, Donado-Gómez JH. Características sociodemográficas y clínicas de pacientes con diagnóstico nuevo de VIH. Infectio 2019;23(3):246-251

30. Schuelter-Trevisol F, Custódio G, da Silva ACB, de Oli- veira MB, Wolfart A, Trevisol DJ. HIV, hepatitis B and $\mathrm{C}$, and syphilis prevalence and coinfection among sex workers in southern Brazil. Rev Soc Bras Med Trop. 2013;46(4):493-497.

31. Távora LGF, Hyppolito EB, da Cruz JNM, Portela NMB, Pereira SM, Veras CM. Hepatitis B, C and HIV co-infections soroprevalence in a northeast braziliam center. Arq Gastroenterol. 2013;50(4):277-280.

32. Vinikoor MJ, Mulenga L, Siyunda A, Musukuma K, Chilengi R, Bolton-Moore C, et al Association between hepatitis B co-infection and elevated liver stiffness among HIV-infected adults in Lusaka, Zambia. Trop Med Int Health 2016;21(11):1435-1441.

33. Téllez-Pérez F, Ríos-Villegas MJ. Mohamed-Balghata MO. Epidemiología de la hepatitis $C$ en el paciente infectado por el VIH. En: Rivero-Román A, Pineda JA, eds. Coinfección por VIH y VHC. Tafics; 2012. p. 2936.

34. Calvo F, Giralt C, Turró O. Tuberculosis, Virus de la Inmunodeficiencia Humana y Virus de la Hepatitis C en población sin hogar. Index de Enfermería [Index Enferm] (edición digital) [en línea] 2016; [Consultado el 08 de jun 2019] 25(4). Disponible en: http://www. index-f.com/index-enfermeria/v25n4/10630r.php

35. Ramírez-González LE, Piñeirua-Menendez A, Badial-Hernández F, Sánchez-Ávila JF, Pérez-Carrizosa A, Camiro-Zúñiga $A$, et al. Características demográficas y clínicas de pacientes coinfectados por VIH y Virus de Hepatitis C en México. Revista Médica MD 2018;9(4):294-298.

36. Platt L, Easterbrook P, Gower E, McDonald B, Sabin K, McGowan C, et al. Prevalence and burden of HCV co-infection in people living with HIV: a global systematic review and meta-analysis. Lancet Infect Dis. 2016;16(7):797-808.

37. Alvarez L, Tejada-Llacsa PJ, Melgarejo-García G, Berto G, Montes Teves P, Monge E. Prevalencia de hepatitis B y C en el banco de sangre de un hospital en Callao, Perú. Rev Gastroenterol Peru. 2017;37(4):346-349.

38. Osimani ML, Latorre L, Garibotto G, Scarlatta L, Chiparelli H, Vidal J. VIH, Hepatitis B, Hepatitis C y VDRL en usuarios de cocaína no inyectable en Uruguay. Adicciones 2005;17(2):157-162.

39. Cruz-Bermúdez HF, Moreno-Collazos JE. Seroprevalencia de tamizaje de Chagas y factores asociados a coinfección en un banco de sangre de Colombia durante 2006-2011. Rev Méd. Risaralda. 2015;21(1):2630. 